\title{
Night Cooled Radiant Cooling Panel for Sustainable Building Cooling Mode in Malaysia
}

\author{
Azhaili Baharun', "Muhammad Syukri Imran', Siti Halipah Ibrahim' and \\ Wan Azlan Wan Zainal Abidin²
}

Published online: 31 August 2018

To cite this article: Azhaili Baharun, Muhammad Syukri Imran, Siti Halipah Ibrahim and Wan Azlan Wan Zainal Abidin (2018). Night cooled radiant cooling panel for sustainable building cooling mode in Malaysia. Journal of Construction in Developing Countries, 23(1): 61-79. https://doi.org/10.21315/jcdc2018.23.1.4.

To link to this article: https://doi.org/10.21315/jcdc2018.23.1.4

\begin{abstract}
Night air temperature in Malaysia is generally about $23^{\circ} \mathrm{C}$ and is a potential source of heat sink to dissipate heat gain from a building. A thermal storage tank was used to store a certain quantity of water and was passively cooled during the night using the pitched roof as a heat exchanger to chill the water to as low as $22^{\circ} \mathrm{C}$. The free cooling of water was then used as a cooling medium to cool the modular radiant cooling panel during the day time when the outdoor temperature exceeds $30^{\circ} \mathrm{C}$. The experiment shows that the system was able to maintain an indoor temperature of less than $28^{\circ} \mathrm{C}$ when the outdoor temperature peaked to nearly $34^{\circ} \mathrm{C}$ while providing acceptable thermal comfort with certain controlled air movement. The use of the hydronic radiant cooling panel with free night cooled water as its coolant is proven to have significant energy saving potential of up to $85 \%$ while at the same time provide an acceptable room thermal comfort which meets the international standard criteria such as the American Society of Heating, Refrigerating and Air-Conditioning Engineers (ASHRAE) Standard 55.
\end{abstract}

Keywords: Night sky cooling, Energy conservation, Thermal comfort, Night cooled water, Passive system

\section{INTRODUCTION}

At present, with the increasing effort to conserve resource and reduce environmental impact, building development needs to adopt sustainability to progress forward. The process of building cooling, particularly in all year hot and humid country like Malaysia, requires a huge amount of energy, therefore, should be the focal point of energy conservation measures. Measures of energy conservations may include incorporating passive building cooling systems rather than fully active mechanical system as well as renewable energy system (Hyde, 2008). Integration of passive and active system is seen as an opportunity to reduce energy consumption and improve building thermal comfort. This technique which is line with the bioclimatic principle of building cooling has become the latest trend in architecture as humans are required to adapt to a rapidly warming world (Gregor, 2014). Linking passive and active system can be seen in many demonstration homes and buildings which prove that building can achieve a high level of environmental sustainability in multiple of ways that will be described more in the following literature.

\footnotetext{
'Faculty of Engineering, Universiti Malaysia Sarawak, 94300 Kota Samarahan, Sarawak, MALAYSIA ${ }^{2}$ Centre for Graduate Studies, Universiti Malaysia Sarawak, 94300 Kota Samarahan, Sarawak, MALAYSIA "Corresponding author: md.syukri@moh.gov.my
} 


\section{LITERATURE REVIEW}

Building active cooling is usually provided by air conditioning and mechanical ventilation system (ACMV). The system often uses refrigerant and chiller unit to provide direct cooling to a building. Chiller unit circulates cold water to room cooling devices such as air handling unit, chilled beam or hydronic radiant panels to provide conditioned air at the required temperature and humidity level. Refrigerant boils at a low temperature and pressure which removes heat from the chill water. The hot refrigerant then condenses in an external condenser unit to reject the heat outdoor for the refrigerant to recover. The process requires electrical energy input to allow for the change of phase of the refrigerant from boiling vapor state to condense liquid state which takes place in a gas compressor unit. Chiller system could be substantial in size given the significant amount of building thermal gains either from solar, people or equipment particularly in a country like Malaysia. Therefore its energy consumption is relatively high as well. Vangtook and Chirarattananon (2007) have reported that air conditioning of building in Southeast Asian region accounts for $60 \%$ for commercial and about $70 \%$ for residential building.

Passive cooling system among others involves the use of cold ambient air and the upper atmosphere as a natural heat sink. This type of cooling system generate the cold thermal energy during the cool nighttime by radiant heat loss from the roof or using special radiator on the roof and transfer the energy to the building during the daytime. In some instances, this is accomplished with the use of a cold thermal storage. The system is effective in any region with low cloud cover at night which is an essential climatic requirement regardless of its air humidity. One example which uses the night sky cold thermal energy is the nocturnal radiative cooling modeling study by Heidarinejad, Farmahini and Delfani (2010) in Tehran. The use of refrigerant as the cooling source was replaced with night time radiator or flat plate radiator where water was circulated through the radiator to cool down water from $28^{\circ} \mathrm{C}$ to about $24^{\circ} \mathrm{C}$. The cold water was stored in a storage tank and used as a cooling medium to charge the cooling coil unit during the daytime. During a typical day, the hot outdoor air was forced through the cooling coil, therefore, lowering the peak outdoor air temperature from $37^{\circ} \mathrm{C}$ to $28^{\circ} \mathrm{C}$. The researchers took advantage of the dry climate in Tehran that has a very low humidity level of about $30 \%$. The precooled air was subjected to evaporative cooling which further decreases the air temperature to about $21^{\circ} \mathrm{C}$, therefore, providing the comfort condition. However, this system is not effective in a high humid climate like Malaysia where a much cooler cooling coil of less than $20^{\circ} \mathrm{C}$ is required to achieve a conditioned air of $21{ }^{\circ} \mathrm{C}$. The night sky temperature condition in Malaysia is just not cold enough to cool water below $20^{\circ} \mathrm{C}$ (Imran et al., 2016[b]) therefore cooling of water is still much dependent on mechanical chiller or refrigerant system. Another type of indoor heat exchanger should be used in place of the cooling coil should the nocturnal or night sky radiator is used.

In Thailand, Vangtook and Chirarattananon (2006) conducted an experiment on radiant cooling in hot and humid climate application. The radiant cooling panels were made from copper coil bonded to copper sheets installed on ceilings and partly on the wall surface of the experimental room. Chill water was circulated through the radiant cooling panels at a constant temperature of $25^{\circ} \mathrm{C}$ (temperature limited to $25^{\circ} \mathrm{C}$ to avoid surface condensation). The panels were able to provide an indoor temperature of about $27^{\circ} \mathrm{C}$ when the outdoor temperature peaked at $34.4^{\circ} \mathrm{C}$. The chill water used in the experiment was provided by a mechanical 
chiller. Another variation of the study by the same researcher investigated the use of radiant cooling panel in combination with a cooling tower (Vangtook and Chirarattananon, 2007). The cooling tower was designed as a means to cool the supply water for the radiant cooling panel. The local climate allows the cooling tower to achieve water temperature of $25^{\circ} \mathrm{C}$ through evaporative cooling at night. Although a computer simulation was used in the study, the result shows that for a given area of the radiant cooling surface, cooling tower operated at both day time and night time could provide thermal comfort, particularly for a residential building. Given this potential, it is of high interest in this study to test such system, particularly in Malaysia. For practical purpose and cost effectiveness, a pitched roof is used in this study in place of the cooling tower, and flat plate radiator mentioned previously. The pitched roof is a typical roof type construction in Malaysian residential building.

Not many significant investigations have been done in Malaysia to determine the feasibility of such system in local condition particularly the combination of nocturnal cooling and indoor radiative cooling. However, a numerical study has shown the potential of night cooling in Malaysian region where an average of $44 \mathrm{~W} / \mathrm{m}^{2}$ of cooling power is achievable by radiative cooling using a flat plate rooftop radiator (Hanif et al., 2014). Imran et al. (2016[d]) showed that combined cooling effect from the evaporative, radiative and convective cooling of water trickled over roof during the night provides a higher average value of $107 \mathrm{~W} / \mathrm{m}^{2}$ where $56 \%$ of the heat loss is attributed to evaporative cooling. Depending on the condition of the evening sky, chill water as low as $23^{\circ} \mathrm{C}$ could be achieved in a region like Malaysia. This chill water, in turn, could be utilised as a cooling medium for indoor heat exchanger such as radiant cooling panels to lower the daytime peak indoor temperature below the outdoor temperature. A conventional radiant cooling panel gets its water supply from a mechanical chiller at a much lower temperature that is usually less than $18^{\circ} \mathrm{C}$. As a result, surface condensation tends to occur on the panels. The night cooled water, however, does not create such problem as the water temperature is high enough to avoid condensation. The cold thermal energy provided by night cooled water is also free and uses a minimal amount of energy for night cooling circulation process. The use of this system requires unobstructed inclined surface such as the pitched roof however such surface is limited or unavailable especially for a high rise building.

A previous experimental study by Imran et al. (2016[a]) on the use of the radiant cooling panel in a test room with passively cooled water has shown some potential in improving the indoor thermal condition. However, the test had only experimented with cool ceiling surface to provide radiant cooling.

The test was carried out in a room with dimension of 1.5 metres wide by 2.4 metres long and 3 metres high. One of the two shorter sides of the room was an external wall that has a small window which is facing south. The room itself was based on the south side of a semi-detached house located in Kuching Sarawak. The ceiling surface was converted into radiant cooling surface using modular radiant panels. The modular radiant panel consisted of clear PVC tubing embedded in a thin layer of screed. The frontal diffusion layer of the panel was made from gypsum board and was painted to give the layer the required high surface absorptivity and emissivity of about 0.8 or greater. The value of 1.0 represents a surface with a perfect absorber or emitter such as a black body. On another hand, a polished aluminum surface has a radiative property of 0.03 only which is not a preferred quality in radiative cooling (Watson and Chapman, 2002). 
The test room setup consisted of a night cooling loop and the indoor radiant cooling water loop. The night cooling loop was operated during the night time only to allow for the cooling of water in the tank. During the daytime, the water in the tank was circulated to the radiant cooling ceiling panels in the test room. The test result showed that the achieved indoor temperature was about $30^{\circ} \mathrm{C}$ or a $2^{\circ} \mathrm{C}$ drop from the base case of $32^{\circ} \mathrm{C}$. The Predicted Mean Vote (PMV) which is an indicator of thermal comfort, improved significantly from 2.3 to 0.45 on the thermal sensation scale. The corresponding air movement, room activity level and clothing insulation value were $0.9 \mathrm{~m} / \mathrm{s}, 1.2$ met (equivalent to a sedentary activity in a residential house) and 0.3 clo respectively. The estimated electrical energy saving from this study was nearly $80 \%$ in comparison to a conventional air conditioning system. The result was promising and that further investigation needs to be done on all surface mode cooling configuration which includes converting wall surface to radiant cooling surface.

\section{Objective of the Study}

The aim of this study is to investigate the performance of the novel modular radiant cooling panel coupled with night cooled water as its cooling medium in a test room setup. The study will determine the level of thermal comfort that could be achieved in the test room as well as the amount of energy saving it could provide in comparison to the conventional active cooling method.

\section{METHODOLOGY}

\section{Test Room Set Up}

The test that was carried out in this study utilised the test room explained in the literature review. The present test differs from the previous test in that the surface cooling areas have been increased to include the wall surface as well. The construction of radiant cooling wall panels was identical to the ceiling radiant panel's construction except for the diffuser layer material type. Painted aluminum sheet was used as the diffuser layer of the wall cooling panels as shown in Figure 1. All the four wall surfaces of the test room have been converted into a radiant cooling surface using multiple vertical radiant cooling panels. The $\mathrm{R}$ value of the wall and ceiling construction after the installation of the radiant wall panel was $1.28 \mathrm{~m}^{2} \mathrm{~K} / \mathrm{W}$ and $2.18 \mathrm{~m}^{2} \mathrm{~K} / \mathrm{W}$ respectively. These values are significantly higher than the base case construction value of $0.28 \mathrm{~m}^{2} \mathrm{~K} / \mathrm{W}$ for wall and $0.20 \mathrm{~m}^{2} \mathrm{~K} / \mathrm{W}$ for the ceiling.

A two-step process was carried out in this experiment. The first step is the cooling of water stored in insulated HDPE tank at night using the pitched roof as a heat exchanger while the second phase involves the cooling of the indoor test room which takes place during the day. The system connection between the two steps is shown in Figure 2. The hydronic radiant cooling panels were connected to the chill water tank of about 1,800 litre in size so that it used the chill water as its cooling medium to cool its surfaces. Radiant heat exchange would occur between the cool surfaces of the radiant panels and other surfaces of the test room such as the wall and floor which is in a straight line of sight. The cool surfaces would also 
indirectly cool the surrounding room air through convection. The measured height from the floor level to the suspended cool ceiling panel was about 2.5 metres. A mini ceiling fan has been installed onto the cool ceiling panel frame in the middle of the test room to allow for occupant-controlled air movement in the room when it is required. The fan could provide an air speed of $1.2 \mathrm{~m} / \mathrm{s}$ or greater at 1.7 metres from the floor level (air speed measurement requirement is elaborated in the following subsection). A water pump was made available to allow circulation of water in the night cooling loop and day cooling loop with a fixed water flow rate of about 0.5 L/s.

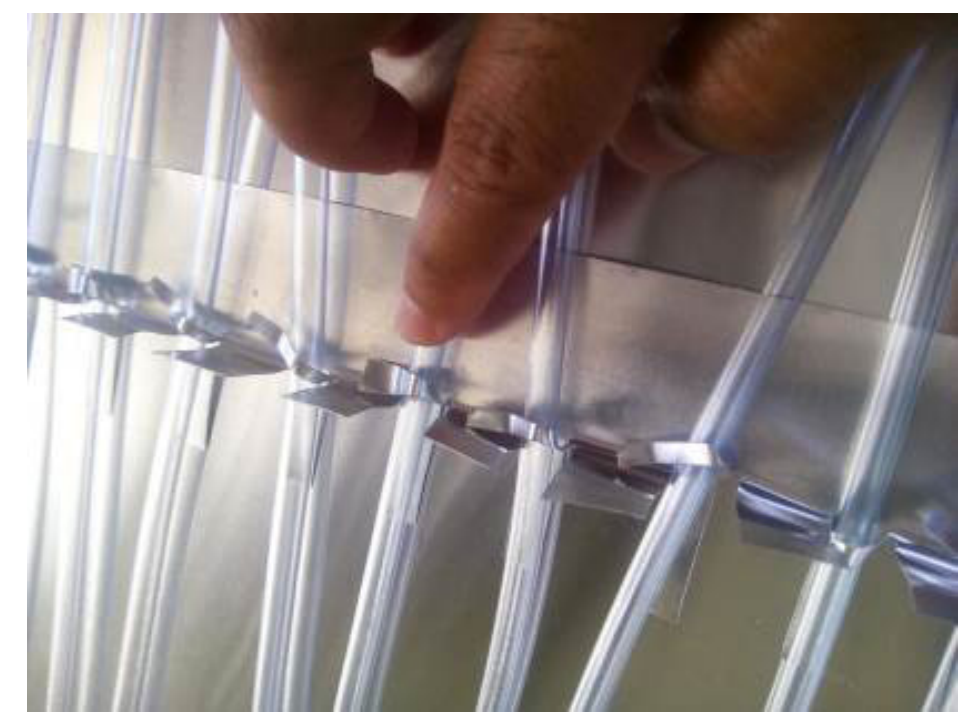

Figure 1. Section View and Photo of the Custom Made Wall Radiant Cooling Panel Assembly

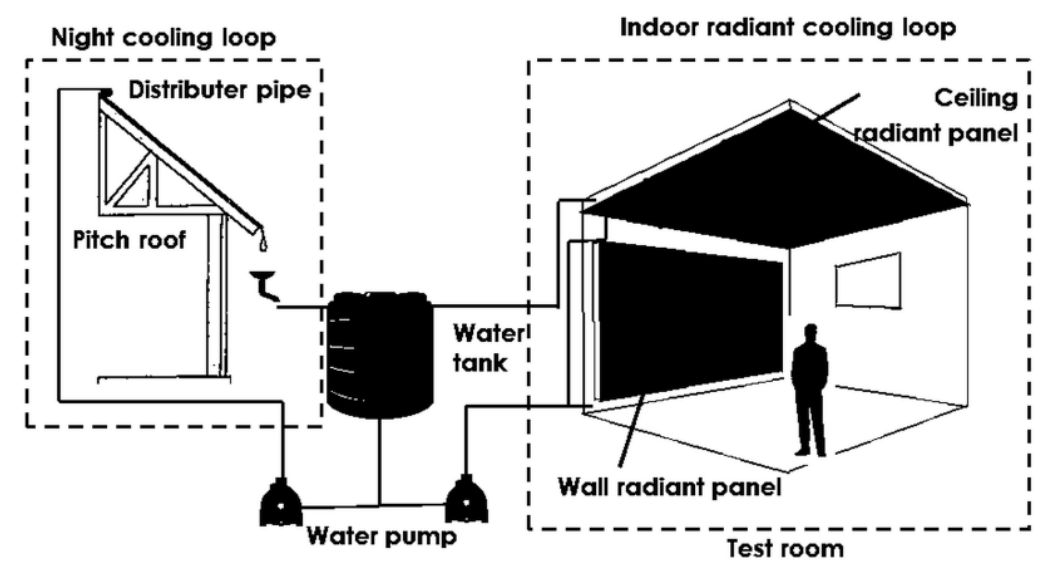

Figure 2. Experimental Set-Up for Indoor Radiant Cooling with Night Cooled Water 
Most of the wall and ceiling in the test room was covered with radiant panels apart from a small area which was insulated with 0.025 metres expanded polystyrene or Styrofoam to reduce the flow of external or "outside" heat flux through the walls and into the test room. The window of the test room was also shaded with an aluminum reflective sheet to minimise the short wave and long wave heat radiation from the sun and outside surrounding, through this way, accumulation of solar heat gain by the internal surfaces would be diminished and would enhance the performance of the radiant cooling panels. The solar heat gain coefficient (SHGC) of the window assembly was about 0.2 which is a major drop from 0.6 without the expanded polystyrene and aluminum reflective sheet. Figure 3 shows the test rig assembly which constitutes both the night cooling loop and the indoor cooling loop that was used to meet the objective of this study.

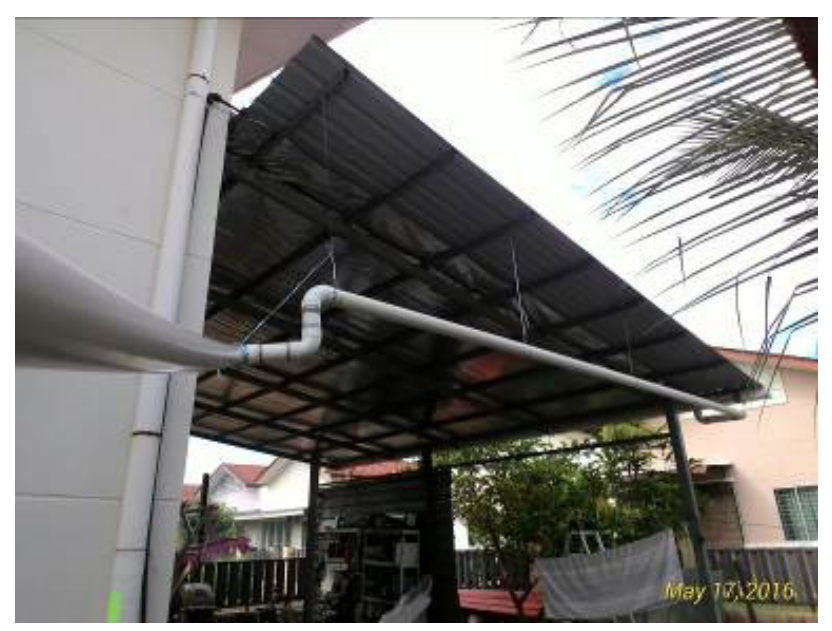

(a)

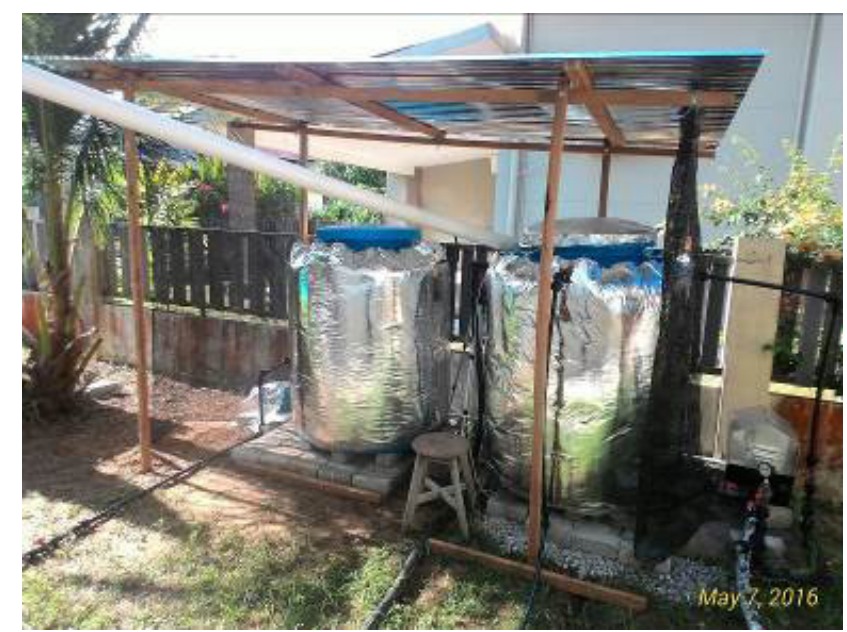

(b) 


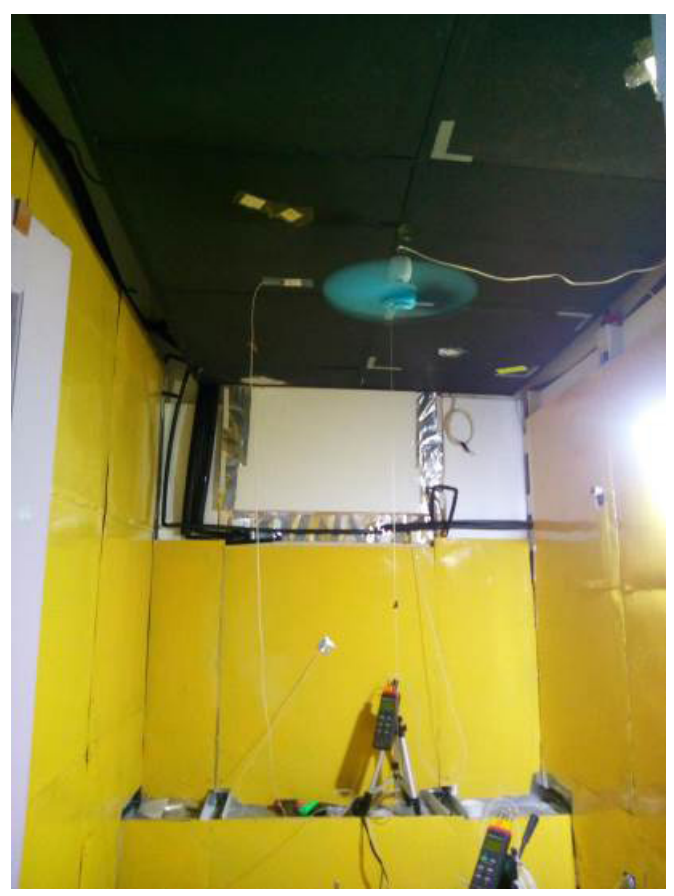

(c)

Figure 3. (a) The Night Cooling Loop as Well as the Indoor Cooling Loop Test Rig Assembly, (b) Thermal Storage Tanks and Pitch Roof as Part of Night Cooling Loop and (c) Test Room with Radiant Cooling Panels (Both on Wall and Ceiling Surface)

\section{Measurement Setup}

For the purpose of thermal comfort evaluation, a few environmental factors needed to be measured such as the air temperature, relative humidity ( $\mathrm{RH})$, mean radiant temperature (MRT) and air speed. Metabolic rate and clothing insulation are another two factors that represent the characteristic of the room occupant and are equally important in determining the thermal comfort condition. All six factors were used to determine the thermal condition of the test room using the Predicted Mean Vote (PMV) index (ISO 2005). The calculated PMV was then compared to the limits set by American Society of Heating, Refrigerating and Air-Conditioning Engineers (ASHRAE) Standard 55 (American National Standards Institute [ANSI]/ ASHRAE, 2013). Another simpler indicator of thermal comfort is the operative temperature. It is defined as the average value of the mean of air temperature and mean radiant temperature. However, PMV method was used in this study as the indoor radiant cooling system and ceiling fan were utilised in this study. The PMV method is recognised by international standards such as ASHRAE Standard 55 as well as ISO 7730. ASHRAE has also recommended that for a mechanically conditioned building, the thermal spaces should be evaluated using the PMV method. 
Thermocouples type $\mathrm{K}$ were used to measure the shielded air temperature in the test room at the $0.1,0.61,1$ and 1.7 metres high from the floor level. The thermocouples were connected to a data logger to take a measurement at every 5 minutes interval as specified by the standard. At the same specified heights, average air speed including $\mathrm{RH}$ was also measured with a handheld metre. ASHRAE Standard 55 specifies that the mean air temperature and air speed is to be taken at 0.1, 0.61 and 1.1 metres for seated occupant while measurement for standing occupants is to be taken at $0.1,1.1$ and 1.7 metres high from floor level. The measurement was made for a minimum of two hours during period deem to be critical times of anticipated occupancy. A standard 0.15-metre globe thermometer was also used to calculate MRT. The following formula was used to convert globe temperature to MRT (ISO, 1998):

$$
M R T=\left[(G T+273)^{4}+2.5 \times 10^{8} \times \nu_{\alpha}^{0.6}\left(G T-T_{\alpha}\right)\right]^{\frac{1}{4}}-273
$$

where,

MRT = mean radiant temperature $\left({ }^{\circ} \mathrm{C}\right)$,

GT = globe temperature $\left({ }^{\circ} \mathrm{C}\right)$,

$\nu_{\alpha}=$ air velocity at level of globe $(\mathrm{m} / \mathrm{s})$ and

$T_{\alpha}=$ air temperature $\left({ }^{\circ} \mathrm{C}\right)$.

The average of mean air temperature and MRT is expressed as operative temperature and is usually used to present thermal comfort evaluation result in graphical form. However, for space cooling which involves radiant cooling surfaces and elevated air speed, ASHRAE Standard 55 (Normative Appendix A) provide a method to determine the operative temperature. A thermal comfort tool software developed by Centre for the Built Environment (CBE) was used in this study to evaluate the thermal comfort condition of the test room in term of PMV. It could be downloaded as a non-commercial license application from the website (Tyler et al., 2013). The work process of inputting value in the thermal comfort tool software is explained in Appendix G of ASHRAE Standard 55 that shows how the final PMV is derived. As the test room is installed with occupant controlled ceiling fan, the increased air movement provided by the fan is taken into account. The thermal comfort tool was used to calculate the corrected PMV value based on the increased air movement according to Standard Effective Model (SET). According to ASHRAE Standard 55, the acceptable PMV value for compliance purpose shall be between -0.5 and +0.5 where neutral PMV value is equal to 0 .

\section{Simulation with Energy Plus}

The test room has a limitation in providing a whole building energy consumption analysis. Therefore, a building energy simulation computer program; i.e., Energy Plus was used to overcome this. Energy Plus is among the 20 major building simulation program (Crawley et al., 2008) being used widely by both building designers as well as researchers. It is a freeware program that has a spreadsheet-like interface with 
some other tools to manage the simulation as well as display results. US Department of Energy (USDOE) who develops Energy Plus, have released another freeware; i.e., Open Studio to support simulation with Energy Plus. Open studio offers a combo of application which allows the user to create Energy Plus model in 3D, easily view or modify the model envelope, loads, schedules and ACMV as well as viewing and exporting result. Energy Plus has gone through several types of validation test such as the comparative building energy simulation test (Henninger and Witte, 2004), analytical test (Henninger and Witte, 2015) as well as an empirical test (Hong et al., 2013) which confirms that the program is working as intended. An independent validation work to increase the level of confidence of Energy Plus has also been carried out by Imran et al. (2016 [c]) where field data set have been used to validate the results predicted by Energy Plus. Energy Plus was selected in this study to perform an annual analysis of energy consumption as not only it is recommended by MS 1525 but it has the features to meet all the criteria set by the standard with regards to building energy simulation programs (Standard Malaysia, 2007). Another reason why Energy Plus was chosen is that it employs heat balance method (simultaneous calculation of radiation and convection processes) to calculate the building cooling load. According to Bauman, Schiavon and Feng (2013), the heat balance method should be used particularly for radiant cooling system modeling. Energy Plus is one of the energy simulation programs that has the capability to model radiant heating and cooling system (Crawley et al., 2000) which suits the need of this research.

The model creation process and simulation is discussed briefly here. First, the Energy Plus model was created using Open Studio plugin. It allows the geometry of the building to be created in a 3D modeling program or SketchUp. The model was then loaded into Open Studio Application which allows model envelope, loads, schedules and ACMV to be viewed, added or modified before running the simulation. The building geometry, construction type and building thermal load was surveyed and measured manually in this case. Energy Plus also includes a common construction material properties such as the conductivity, density, and specific heat which can be modified when needed. Resources on material properties are readily available from multiple sources so that users are free to define the material property such as from Chartered Institution of Building Services Engineers (CIBSE) Guide A (CIBSE, 2004) and from building construction handbook (Roy and Roger, 2008). The simulation was carried out thrice in this study to compare the energy consumption of the base case building, radiant cooling system and conventional air cooling system. Finally, the result could be viewed using the Open Studio result viewer, which produce time series line and flood plot for variable requested such as the building energy consumption.

\section{RESULTS AND DISCUSSIONS}

Table 1 provides a summary of a multiple night cooling process which was carried out at different nights for different water cooling mode. Water pumping duration and time of operation was manipulated for each cooling mode which also included a rainfall event. It can be seen here that a rainfall event and dawn cooling could be adopted as a good cooling strategy to cool the water tank while reducing pump operation time to reduce energy. This strategy allows for more efficient night cooling as less energy is being used for over $70 \%$ cooling output. For example, a dawn cooling mode with only two hours of pump operation could achieve about 
$70 \%$ of cooling potential whereas the all night cooling mode requires about four hours of pump operation time to achieve the same cooling output. Another eight hours of pumping was needed to achieve the other $30 \%$ cooling. It is therefore recommended to carry out dawn cooling where the higher cooling rate and cooling output could be achieved.

Table 1. Different Night Cooling Mode that Affects Percentage of Cooling Achieved

\begin{tabular}{lcccccc}
\hline $\begin{array}{l}\text { Cooling } \\
\text { Mode }\end{array}$ & $\begin{array}{c}\text { Hours of } \\
\text { Pumping }\end{array}$ & $\begin{array}{c}\text { Initial Tank } \\
\text { Water Temp. } \\
\left({ }^{\circ} \mathrm{C}\right)\end{array}$ & $\begin{array}{c}\text { Tank Water } \\
\text { Temp. at } \\
\text { 7am }\left({ }^{\circ} \mathrm{C}\right)\end{array}$ & $\begin{array}{c}\text { Outdoor Dry Bulb } \\
\text { Temperature } \\
\text { (DBT) at 7 am }\left({ }^{\circ} \mathrm{C}\right)\end{array}$ & $\begin{array}{c}\text { \% Cooling } \\
\text { Achieved }\end{array}$ & $\begin{array}{c}\text { Final Hour } \\
\text { Temp. Diff.* } \\
\left({ }^{\circ} \mathrm{C}\right)\end{array}$ \\
\hline $\begin{array}{l}\text { All night } \\
\text { cooling }\end{array}$ & 12 & 28.9 & 25.5 & 25.2 & $92 \%$ & 0.3 \\
$\begin{array}{l}\text { Rain } \\
\text { cooling } \\
+ \text { dawn } \\
\text { cooling }\end{array}$ & 2 & 31.6 & 26.2 & 24.8 & $79 \%$ & 1.4 \\
$\begin{array}{l}\text { Dawn } \\
\text { cooling }\end{array}$ & 2 & 27.5 & 25.9 & 25.2 & $70 \%$ & 0.7 \\
$\begin{array}{l}\text { Pre cool } \\
\text { and } \\
\text { dawn } \\
\text { cooling }\end{array}$ & 4 & 29 & 26.8 & 25 & $55 \%$ & 1.8 \\
\hline
\end{tabular}

Note: *Temperature difference between DBT and tank water temperature

Figure 4 shows a comparison of mean air temperature between the test room and a control room that is located next to the test room and is similar in dimensions as well as envelope construction type.

The figure shows the indoor air temperature in both rooms peaked at around $5 \mathrm{pm}$ in the afternoon. The indoor peak temperature occurs a few hours behind the outdoor peak air temperature. The time lag is not uncommon in building with a particular type of construction. Building with higher mass construction has the capacity to reduce and delay its peak indoor temperature for several hours by storing the heat in its building mass and re-radiate the heat back to the space at night (Baker, 1987). It was decided that radiant cooling panel would be operated to coincide with the indoor peak temperature of the test room or between $3 \mathrm{pm}$ and $7 \mathrm{pm}$. In general, the base case PMV for the test room was 2.3 given the peak air temperature of $31.9^{\circ} \mathrm{C}, 85 \%$ humidity and air speed of $0.15 \mathrm{~m} / \mathrm{s}$. The calculated PMV value was based on a metabolic rate of 1.2 met and a clothing insulation value of $0.3 \mathrm{clo}$. If the air speed were to be increased to $1.2 \mathrm{~m} / \mathrm{s}$, the corresponding PMV is about 1.1 and is still considered very high. These PMV values were used as the base case value to represent the test room thermal condition before the installation of the indoor radiant cooling system. The control room indoor thermal condition is such that it did not meet the thermal comfort standard set by ASHRAE Standard 55 as well as ISO 7730. The hot room condition is in agreement with investigations by other local researchers such as Imran et al. (2016 [b]), Ibrahim and Tinker (2005), Rajeh (1994), Nugroho (2011), Kamar et al. (2012) as well as Normah, Lau and Mohd 
Yusoff (2012). These researchers have shown that typical Malaysian residential house including low-income house have failed to provide the minimum thermal comfort target. A study by Djamila, Chu and Kumaresan (2013) in a similar regional condition located in Sabah, Malaysia has shown from a survey that the thermal comfort temperature was at $30.2^{\circ} \mathrm{C}$. Another study by Hussein, Rahman and Maria (2009) has given an upper limit of $30.7^{\circ} \mathrm{C}$ for an unconditioned building in Malaysia. A similar study by Nguyen, Singh and Reter (2012) has put not more than $30^{\circ} \mathrm{C}$ as an upper limit for building in a hot and humid region. In short, the control room did not satisfy both the international standard as well as the local research findings.

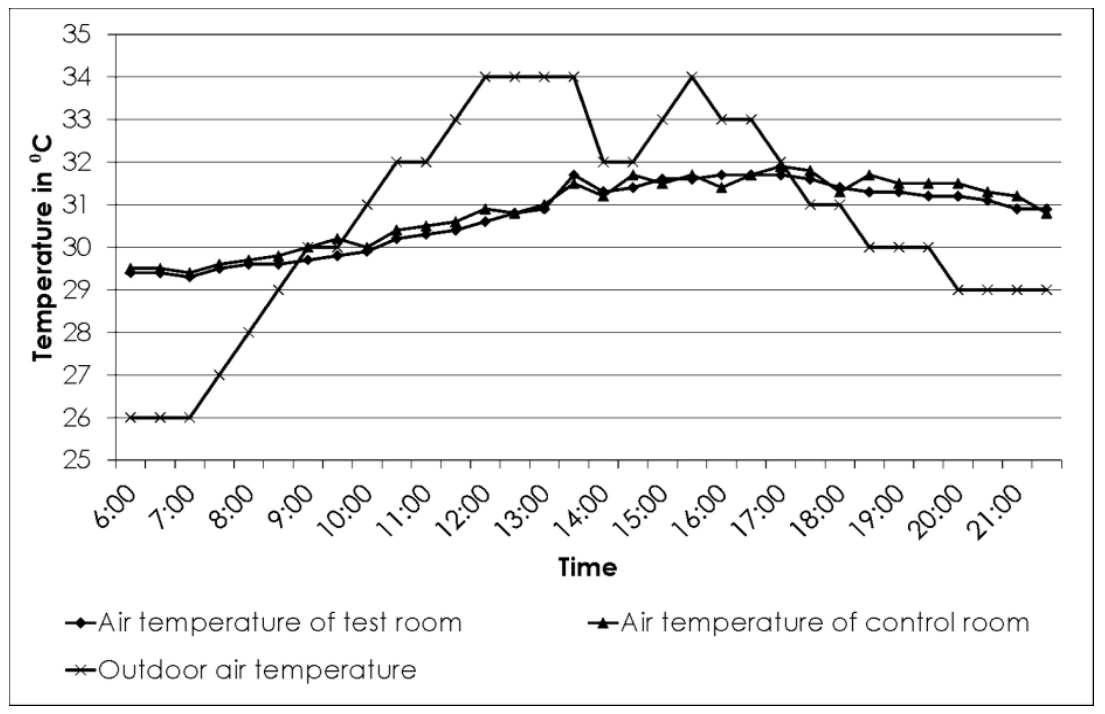

Figure 4. Comparison of Mean Air Temperature for Test and Control Room Taken on 18 April 2016

Figure 5 shows the effect of the presence of the radiant panels both vertically and horizontally combined with forced air movement in the test room.

Before the start-up of the pump, there exists a certain amount of mean air temperature depression in the test room in comparison to the control room. This temperature drop is due to the increased $R$ value of the wall surfaces after the installation of radiant wall panel which helps to reduce the amount of external heat gain or heat flux into the test room. This condition is very much advantageous for the radiant cooling panel performance in the test room. While the control room temperature continues to rise, the test room temperature drops significantly during the time the pump was operated to circulate the chill water into the radiant panels. A maximum of $4^{\circ} \mathrm{C}$ temperature drop was recorded during the critical hour of cooling in the test room while the lowest air temperature recorded in the test room was $26.5^{\circ} \mathrm{C}$. The calculated PMV value for both standing occupant level (1.1 metres from floor level) and seated occupant level (0.6 metres from floor level) is shown in Table 2. Given the average air speed at seated occupant level, the PMV value is within the acceptable PMV value $(-0.5<\mathrm{PMV}<+0.5)$ as specified by ASHRAE Standard 55. However, for a standing occupant level, the PMV was slightly 
outside the acceptable range with a slightly cool sensation. A neutral sensation was achieved when the occupant clothing insulation value was increased to 0.5. A 0.5 clothing insulation value represents an occupant garment combination of underpants with short sleeves shirt, light trousers wearing socks and shoe while a lower 0.3 clothing insulation value represents an occupant wearing T-shirt, short and light socks with sandals (ISO, 2005). A clo value between 0.3 and 0.5 is what one would expect from an occupant living in a Malaysian residential house. The metabolic rate of 1.2 which was selected in the calculation of PMV represents an occupant in a state of sedentary activity such as standing in a relax state.

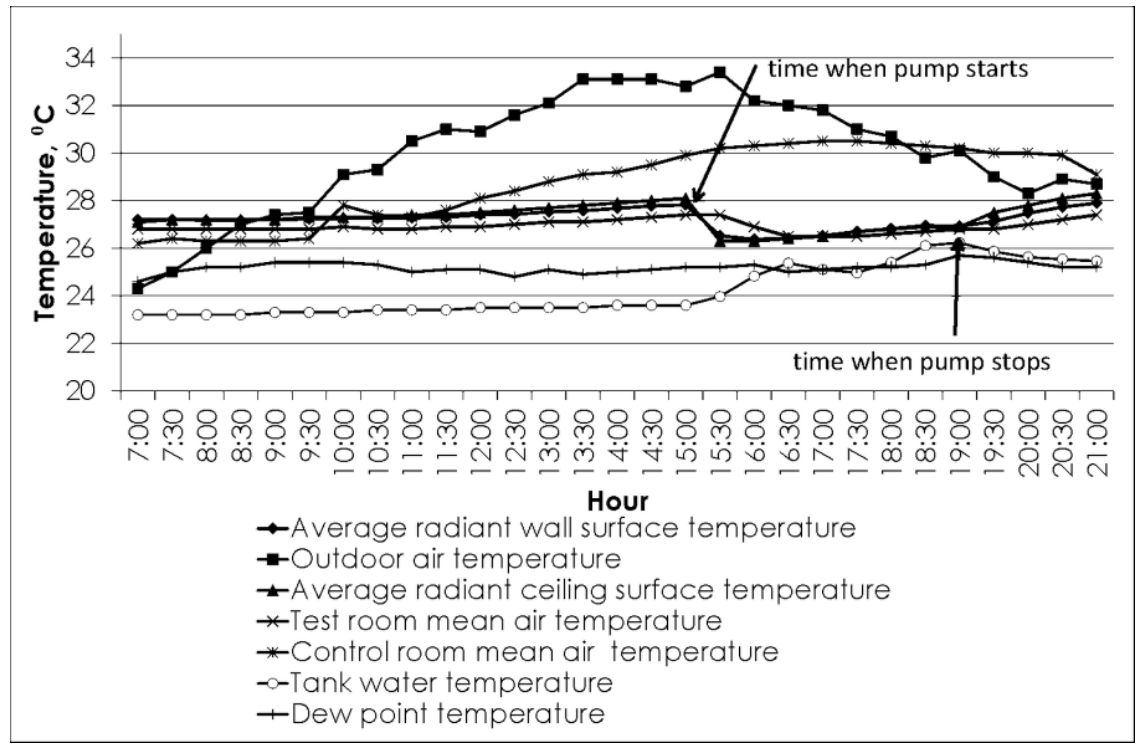

Figure 5. Effect of Radiant Ceiling and Wall Panel Operated with Forced Air Movement in the Test Room on 27 July 2016

Figure 6 shows the graphical representation of the test room before and after the installation of the radiant cooling panels. The acceptable thermal comfort zone is defined by the bounded area in the chart and was calculated using the CBE thermal comfort tool software. Given the measured operative temperature and the average airspeed for seated and standing occupant, it could be determined that the thermal condition of the test room is within the acceptable thermal comfort range. The thermal condition is found to be within the confined area in the figure given a clothing insulation value of 0.5 and metabolic rate of 1.2. 
Table 2. Calculated PMV for Clothing Insulation Value between 0.3 and 0.5 at Standing and Seated Occupant Level

\begin{tabular}{lcccc}
\hline \multicolumn{1}{c}{ Thermal Comfort Parameter } & \multicolumn{2}{c}{ Seated Occupant Level } & \multicolumn{2}{c}{ Standing Occupant Level } \\
\hline Metabolic rate & 1.2 & 1.2 & 1.2 & 1.2 \\
Clothing insulation value & 0.3 & 0.5 & 0.3 & 0.5 \\
Average operative temperature & 26.7 & 26.7 & 26.7 & 26.7 \\
$\left({ }^{\circ} \mathrm{C}\right)$ & & & & \\
Compliance & $\sqrt{ }$ & $V$ & $\times$ & $\sqrt{ }$ \\
PMV with elevated air & -0.35 & 0.12 & -0.63 & -0.1 \\
PPD with elevated air $(\%)$ & 8 & 5 & 13 & 5 \\
& & & & \\
Sensation & Neutral & Neutral & Slightly Cool & Neutral \\
& & & & \\
SET ( $\left.{ }^{\circ} \mathrm{C}\right)$ & 23.6 & 25.9 & 22.5 & 24.9 \\
Drybulb temp at still air $\left({ }^{\circ} \mathrm{C}\right)$ & 24.2 & 24.3 & 23.5 & 23.6 \\
Cooling effect $\left({ }^{\circ} \mathrm{C}\right)$ & 2.5 & 2.4 & 3.2 & 3.1 \\
Air speed $(\mathrm{m} / \mathrm{s})$ & 0.48 & 0.48 & 0.75 & 0.75 \\
\hline
\end{tabular}

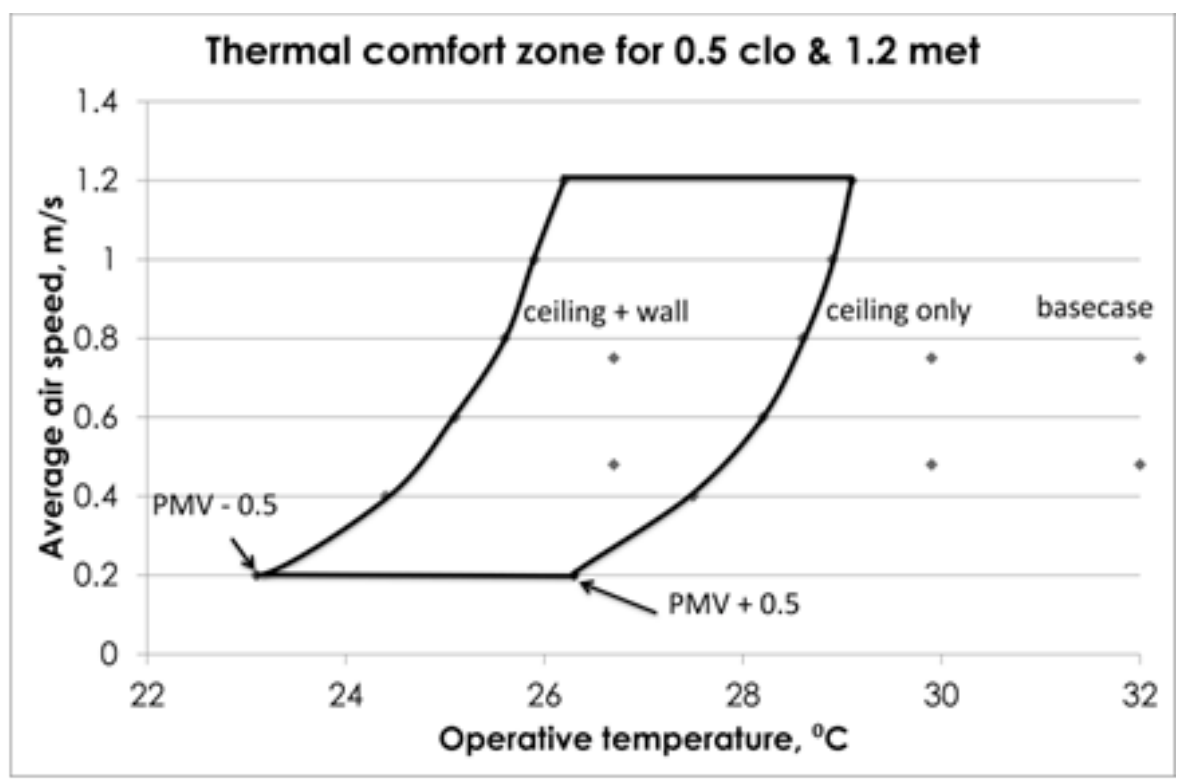

Figure 6. Test Room Thermal Condition for Standing and Seated Occupant

The test shows that the room ceiling and wall surface needs to be converted to the radiant cooling surface to improve its thermal condition from the base case value. Converting ceiling surface only to radiant cooling surface did manage to lower the base case operative temperature as shown in the stage one experiment 
result by Imran et al. (2016[a]). However, it did not provide enough cooling to give an operative temperature that is within the acceptable thermal comfort range. On the other hand, with the added radiant cooling surface provided by the radiant wall panels, the operative temperature is improved significantly to meet the acceptable thermal comfort zone. Thermal comfort is primarily influenced by heat exchange by radiation as well as convection between the occupant and the thermal environment. Use of radiant cooling panels can lower the indoor surface temperature where the long wave radiation cools the surrounding room surfaces, which then indirectly cools the room air. As the room window is shaded from solar radiation, the indoor air temperature tends to follow the surface temperature of the room closely. In this case, the operative temperature is calculated as the average of the mean air temperature and the mean surface radiant temperature of the room. It means the air temperature and radiant temperature have equal influence on the thermal comfort. However, due to the elevated air movement in the room, the operative temperature should be adjusted according to the formula given in ASHRAE Standard 55 to account for the reduced radiant heat transfer and increased convection heat transfer. The average operative temperature of the test room during the critical hour was $26.7^{\circ} \mathrm{C}$ with a corresponding average water tank temperature of $25.4^{\circ} \mathrm{C}$. In order to achieve the same operative temperature, a conventional air cooling system would need to deliver a much cooler air in comparison to the surface temperature of the room. For example, if the room mean radiant temperature is $32^{\circ} \mathrm{C}$, then an air temperature of $21.4^{\circ} \mathrm{C}$ is required to give an operative temperature of $26.7^{\circ} \mathrm{C}$.

Another important aspect of the study is the energy consumption of the radiant cooling system as well as the night cooling loop which is supplying the chilled water source. As there is a limitation in the experimental set up to provide an annual electrical energy consumption for a whole building, therefore, a building energy simulation tool; i.e., Energy Plus was used to predict the annual energy usage of the system. Three simulations were conducted to represent different building cooling mode. One simulation is performed to represent a reference building referred to as the base case building, another to constitute a building with conventional air cooling system and the third simulation to represent a radiant cooling retrofitted building. An annual simulation run (8,760 hours) was carried out which also includes a design day with a peak outdoor temperature of $34^{\circ} \mathrm{C}$. However, for a fair system output comparison, both air cooling system and radiant cooling system models were simulated so that the operative temperature of a selected thermal zone will coincide with each other as shown in Figure 7. The operational scheme for both cooling systems was such that, room cooling was only provided during the critical hour of the day which is between $2 \mathrm{pm}$ and $7 \mathrm{pm}$ daily. Given the similar operation time and operative temperature, the energy consumption of both models was then evaluated. As for the thermal storage tank which supplies the chill water to the radiant cooling system, the charging of the tank was set at $2 \mathrm{am}$, to $7 \mathrm{am}$ in the morning. 


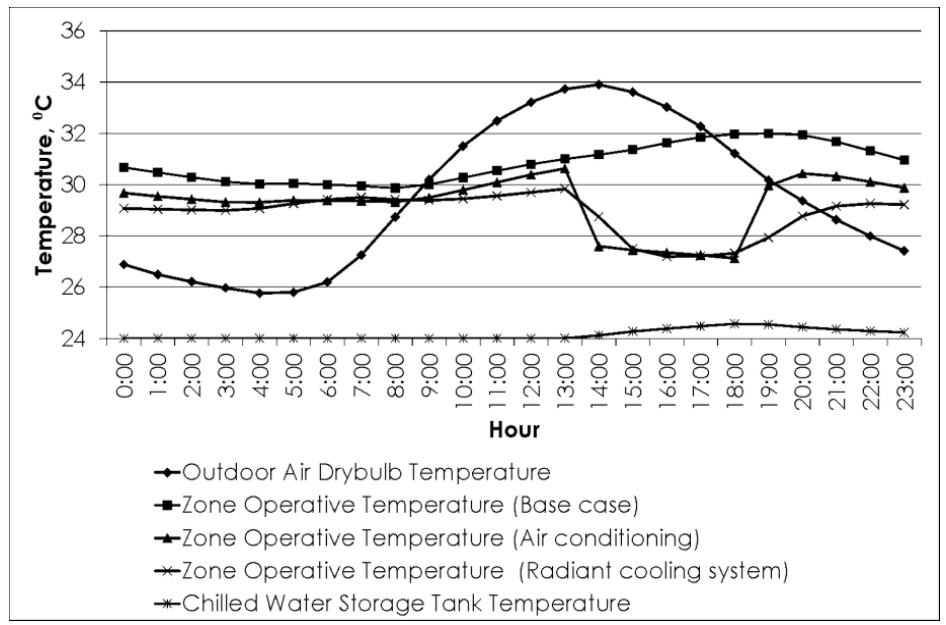

Figure 7. Air system and Radiant System Performance for a Thermal Zone in the Energy Plus Model

Table 3 provides an annual energy comparison between the base case, air cooling system and radiant cooling system. Between $2 \mathrm{pm}$ and $7 \mathrm{pm}$, the operative temperature for both models with air and the radiant cooling system is the same. The maximum indoor temperature drop provided by both systems is about $4^{\circ} \mathrm{C}$ from base case value of $31.8^{\circ} \mathrm{C}$. However, the amount of energy used in term of kilowatthours differs greatly between both cooling systems. The simulation showed that for the same cooling output, the radiant cooling system consumes only $15 \%$ of the energy used to run an air cooling system which gives equivalent savings up to $85 \%$. This amount of saving is not impossible because the radiant cooling system does not utilise gas compressors or refrigerant pump other than low powered water pump in the cooling process. The simulation is in agreement with Nielsen (2012) which states that combining a radiant cooling system with a free cooling source can reduce energy consumption by $80 \%-90 \%$. It is well known that the heat transfer capacity of water is higher than air. In convection cooling, an air cooling system requires a blower to circulate cold air in a room at a certain rate to achieve the required amount of heat transfer. Radiant cooling system using water circulator in place of a fan to move air use less energy and still give the same amount of heat transfer (Uponor Inc, 2013). As shown in the simulation findings, radiant cooling requires less than one-third of the energy needed to operate an air cooling system while could still provide an acceptable indoor thermal condition. 
Table 3. Prediction of Annual Energy Savings from Night Cooled Radiant Cooling System and Payback Period

\begin{tabular}{|c|c|c|c|}
\hline Item & Base Case & $\begin{array}{l}\text { Conventional Air } \\
\text { Conditioning System }\end{array}$ & $\begin{array}{l}\text { Radiant System with } \\
\text { Night Cooled Water }\end{array}$ \\
\hline System set point & - & 25 & 24 \\
\hline $\begin{array}{l}\text { Indoor temperature } \\
\text { (5pm) }\end{array}$ & 31.8 & 27.2 & 27.2 \\
\hline $\begin{array}{l}\text { Cooling energy, kWh } \\
\text { (2pm-7pm) }\end{array}$ & & 7,869 & 1,158 \\
\hline $\begin{array}{l}\text { Annual energy cost } \\
\text { (RM) }\end{array}$ & & 2,360 & 347 \\
\hline \% energy saving & & & $85 \%$ \\
\hline Monetary saving (RM) & & & 2,013 \\
\hline $\begin{array}{l}\text { Estimated all in radiant } \\
\text { system cost per square } \\
\text { meter (RM) }\end{array}$ & & & 40 \\
\hline $\begin{array}{l}\text { Total radiating surface } \\
\text { area, } \mathrm{m}^{2}\end{array}$ & & & 270 \\
\hline $\begin{array}{l}\text { Total estimated cooling } \\
\text { system cost (RM) }\end{array}$ & & 6,500 & 10,800 \\
\hline $\begin{array}{l}\text { Additional investment } \\
\text { cost (RM) }\end{array}$ & & & 4,300 \\
\hline Payback period (years) & & & 2.1 \\
\hline
\end{tabular}

Another interesting point is the financial saving that could be used to pay for the system investment. The additional first cost of the radiant cooling system in comparison to the conventional air cooling system cooling could be recovered within two years as shown in the table.

\section{CONCLUSION}

Experimental work on a novel modular radiant cooling panel with renewable night cooled water in a test room is presented here. The ceiling cooling mode test was not sufficient to improve the indoor thermal condition of the test room. However, in the combined wall, and ceiling cooling mode test, the operative temperature, and PMV are greatly improved and can satisfy the thermal comfort standard. From the computer simulation work, the energy saving potential for this system is very high as it involves the combination of the active and passive method of cooling to maintain a desirable indoor thermal comfort. On the other hand, the large monetary saving contributed by this system allows for a quick payback period. Therefore the radiant cooling panel with renewable night cooled water has a high potential in Malaysian climate application for a more sustainable building cooling system. 


\section{REFERENCES}

American National Standards Institute (ANSI)/American Society of Heating, Refrigerating and Air-Conditioning Engineers (ASHRAE) (2013). Standard 552013 Thermal Environmental Conditions for Human Occupancy. Atlanta: ASHRAE.

Baker, N.V. (1987). Passive and Low Energy Building Design for Tropical Island Climates. London: The Commonwealth Secretariat.

Bauman, F., Schiavon, S. and Feng, J. (2013). Cooling load calculations for radiant systems are they the same as traditional methods? ASHRAE Journal, 55(December): 20-27.

Chartered Institution of Building Services Engineers (CIBSE) (2004). Energy Efficiency in Buildings: CIBSE Guide. London: Chartered Institution of Building Services Engineers.

Crawley, B.D.B., Pedersen, C.O., Lawrie, L.K. and Winkelmann, F.C. (2000). EnergyPlus: Energy Simulation Program. ASHRAE Journal, 42(April): 49-56.

Crawley, D.B., Hand, J.W., Kummert, M. and Griffith, B.T. (2008). Contrasting the capabilities of building energy performance simulation programs. Building and Environment, 43(4): 661-673. https://doi.org/10.1016/j.buildenv.2006.10.027.

Djamila, H., Chu, C.M. and Kumaresan, S. (2013). Field study of thermal comfort in residential buildings in the equatorial hot-humid climate of Malaysia. Building and Environment, 62: 133-142. https://doi.org/10.1016/j.buildenv.2013.01.017. Gregor, A. (2014). Bioclimatic Design. Washington DC: U.S. Green Building Council.

Hanif, M., Mahlia, T.M.I., Zare, A., Saksahdan, T.J. and Metselaar, H.S.C. (2014). Potential energy savings by radiative cooling system for a building in tropical climate. Renewable and Sustainable Energy Reviews, 32: 642-50. https://doi. org/10.1016/j.rser.2014.01.053.

Heidarinejad, G., Farmahini, M. and Delfani, S. (2010). Investigation of a hybrid system of nocturnal radiative cooling and direct evaporative cooling. Building and Environment, 45(6): 1521-1528. https://doi.org/10.1016/j.buildenv.2010.01.003.

Henninger, R.H. and Witte, M.J. (2015). EnergyPlus Testing with ASHRAE 1052-RP Toolkit: Building Fabric Analytical Tests. Washington DC: U.S. Department of Energy.

(2004). EnergyPlus Testing with ANSI/ASHRAE Standard 140-2001 (BESTEST). Washington DC: U.S. Department of Energy.

Hong, T., Buhl, W., Haves, P., Nouidui, T., Wetter, M., Vidanovic, S. and Roth, A. (2013). An Update on Energy Plus. Oak Ridge, TN: US Department of Energy.

Hussein, I., Rahman, M.H.A. and Maria, T. (2009). Field studies on thermal comfort of air-conditioned and non-air-conditioned buildings in Malaysia. Paper presented at the 3rd International Conference on Energy and Environment (ICEE 2009): Advancement towards Global Sustainability. Malacca, Malaysia, 7-8 December. https://doi.org/10.1 109/ICEENVIRON.2009.5398622.

Hyde, R. (2008). Bioclimatic Housing: Innovative Design for Warm Climate. London: Earthscan.

Ibrahim, S.H. and Tinker, J.A. (2005). Improvements to thermal comfort in low-income housing in Malaysia. Paper presented at the Conference on Sustainable Building South East Asia. Kuala Lumpur, Malaysia, 11-13 April. 
Imran, M.S., Baharun, A., Ibrahim, S.H. and Abidin, W.A.W.Z. (2016a). Evaluation of low cost radiant cooling panel in a test room with passively cooled water. Paper presented at the 2nd International Conference of Multidisciplinary Academic Research and Global Innovation. Beijing, China, 25-26 August. . (2016b). Nocturnal cooling of water as free cooling source for building indoor radiant cooling in Malaysian climate. Applied Mechanics and Materials, 833: 94-101. https://doi.org/10.4028/www.scientific.net/AMM.833.94.

. (2016c). Renewable indoor radiant cooling and earth tube heat exchanger hybrid for thermal comfort improvement. Journal of Building Performance, 7(1): 56-71.

. (2016d). Renewable night cooled chill water source for energy efficient indoor radiant cooling. International Journal of Engineering Research in Africa, 26: 86-98. https://doi.org/10.4028/www.scientific.net/JERA.26.86.

International Organization for Standardization (ISO) (2005). EN ISO 7730 Ergonomics of the Thermal Environment: Analytical Determination and Interpretation of Thermal Comfort Using Calculation of the PMV and PPD Indices and Local Thermal Comfort Criteria. 3rd Ed. Geneva: ISO.

- (1998). ISO 7726 Ergonomics of the Thermal Environment: Instruments for Measuring Physical Quantities. Geneva: ISO.

Kamar, H.M., Kamsah, N., Tap, M.M. and Salimin, K.A.M. (2012). Assessment of thermal comfort in a naturally ventilated residential terrace house. Proceedings: The 4th International Meeting of Advances in Thermofluids (IMAT 2011). Mellville, NY: AlP Publishing, 247-254. https://doi.org/10.1016/j.buildenv.2012.03.021.

Nguyen, A.T., Singh, M.K. and Reiter, S. (2012). An adaptive thermal comfort model for hot humid South-East Asia. Building and Environment, 56: 291-300. https:// doi.org/10.1016/j.buildenv.2012.03.021.

Nielsen, L.S. (2012). Building integrated system design for sustainable heating and cooling. REHVA Journal, February: 24-27.

Normah, M.G., Lau, K.Y. and Mohd Yusoff, S. (2012). Thermal analysis of Malaysian double storey housing: Low/medium cost unit. Proceedings: The 4th International Meeting of Advances in Thermofluids (IMAT 2011). Mellville, NY: AIP Publishing, 513-520. Available at: http://scitation.aip.org/content/aip/ proceeding/aipcp/10.1063/1.4704257 [Accessed on 30 January 2015].

Nugroho, A.M. (2011). A preliminary study of thermal environment in Malaysia's terraced houses. Journal of Economics and Engineering, 2(1): 25-29.

Rajeh, S. (1994). Wind Ventilation of Terrace Housing in Malaysia. Kuala Lumpur: ISIUTM International Convention and Exposition.

Roy, C. and Roger, G. (2008). Building Construction Handbook. 7th Ed. Burlington, $\mathrm{NJ}$ : Butterworth Heinemann.

Standard Malaysia (2007). MS 1525:2007 Code of Practice on Energy Efficiency and Use of Renewable Energy for Non Residential Building, Department of Standard Malaysia. 1st Ed. Kuala Lumpur: Department of Standards Malaysia.

Tyler, H., Stefano, S., Alberto, P., Dustin, M. and Kyle, S. (2013). CBE Thermal Comfort Tool. Berkeley, CA: Center for the Built Environment, University of California. Available at: http://cbe.berkeley.edu/comforttool/.

Uponor Inc. (2013). UPONOR Radiant Cooling Design Manual. 1st Ed. Apple Valley, $\mathrm{MN}$ : Uponor Inc. 
Vangtook, P. and Chirarattananon, S. (2007). Application of radiant cooling as a passive cooling option in hot humid climate. Building and Environment, 42(2): 543-556. https://doi.org/10.1016/j.buildenv.2005.09.014.

. (2006). An experimental investigation of application of radiant cooling in hot humid climate. Energy and Buildings, 38(4): 273-285.

Watson, R.D. and Chapman, K.S. (2002). Radiant Heating and Cooling Handbook. New York: McGraw-Hill. 